\title{
An investigation of the factors that regulate muscarinic receptor expression in schizophrenia
}

Myoung Suk Seo ${ }^{\mathrm{a}, \mathrm{b}^{*}}$, Elizabeth Scarr ${ }^{\mathrm{b}, \mathrm{a}}$, Brian Dean $^{\mathrm{a}, \mathrm{b}}$

aThe Molecular Psychiatry Laboratory, The Florey Institute of Neuroscience and Mental Health, Parkville, Victoria 3010, Australia

${ }^{b}$ Department of Psychiatry, The University of Melbourne, Parkville, Victoria 3010, Australia

${ }^{*}$ Corresponding Author: Dr. Myoung Suk Seo

The Molecular Psychiatry Laboratory, The Florey Institute of Neuroscience and Mental Health, Kenneth Myer Building, Genetics Lane, The University of Melbourne, Victoria 3010, Australia.

Email: myoung.seo@florey.edu.au; Telephone: +613-9035-6563; Fax: +613-9035-3107 


\section{Abstract}

We previously identified a group of subjects with schizophrenia who, on average, have a $75 \%$ decrease in cholinergic receptor, muscarinic 1 (CHRM1) in Brodmann's area (BA) 9. To extend this finding, we determined i) if the decrease in CHRM1 was present in another related CNS region (BA6) ii) whether the marked decrease in CHRM1 was accompanied by changes in levels of other CHRMs and iii) potential factors responsible for the decreased CHRM1 expression. We measured CHRM1 and $\mathrm{CHRM} 3$ using in situ radioligand binding with $\left[{ }^{3} \mathrm{H}\right]$ pirenzepine and $\left[{ }^{3} \mathrm{H}\right] 4$-DAMP respectively in BA6 from 20 subjects with schizophrenia who had low levels of CHRM1 in BA9 (SzLow[ $\left.\left.{ }^{3} \mathrm{H}\right] \mathrm{PZP}\right), 18$ subjects with schizophrenia whose levels of CHRM1 were similar to controls (SzNormal[ $\left.\left.{ }^{3} \mathrm{H}\right] \mathrm{PZP}\right)$ and 20 control subjects. Levels of CHRM1, 3 and 4 mRNA were measured using qPCR and levels of the transcription factors, Sp1 and Sp3, determined using Western blots. In BA6, the density of $\left[{ }^{3} \mathrm{H}\right]$ pirenzepine binding was decreased in subjects with SzLow $\left[{ }^{3} \mathrm{H}\right] \mathrm{PZP}(\mathrm{p}<0.001)$ compared to controls. The density of $\left[{ }^{3} \mathrm{H}\right] 4$-DAMP binding, levels of CHRM1, 3 and 4 mRNA and levels of Sp1 and Sp3 were not significantly different between the three groups. This study shows that the previously identified decrease in CHRM1 expression is not confined to the dorsolateral prefrontal cortex but is present in other cortical areas. The effect shows some specificity to CHRM1, with no change in levels of binding to CHRM3. Furthermore, this decrease in CHRM1 does not appear to be associated with low levels of CHRM1 mRNA or to simply be regulated by the transcription factors, Sp1 and Sp3, suggesting that other mechanisms are responsible for the decreased CHRM1 in these subjects.

Keywords: schizophrenia; human; cortex; post-mortem; CHRM1; Sp1 


\section{Introduction}

Schizophrenia is a neuropsychiatric disorder that most likely encompasses a syndrome of diseases with multiple underlying pathologies (Jablensky, 2006). Therefore, one approach to better understand the syndrome of schizophrenia is to study its component disorders (Raedler et al., 2007). We have reported a sub-group (25\%) of people with schizophrenia that can be separated into a separate population within schizophrenia because they have a marked loss $(\sim 70 \%)$ of the levels of $\left[{ }^{3} \mathrm{H}\right]$ pirenzepine binding in BA9 (Scarr et al., 2009), opening up the opportunity to separate people with schizophrenia into two populations based on cortical $\left[{ }^{3} \mathrm{H}\right]$ pirenzepine binding.

We have shown that, under the assay conditions we use, $\left[{ }^{3} \mathrm{H}\right]$ pirenzepine predominately binds to the CHRM1 (Gibbons et al., 2013; Scarr and Dean, 2008). Importantly, clinical and preclinical studies suggest that cortical CHRM1 is important in cognitive functions (Anagnostaras et al., 2003; Nathan et al., 2012). Thus, in this study, we choose to expand our studies on cortical CHRM1 to BA6 because this region of the cortex has been shown to act in concert with BA9 when cognitive tasks such as attention, working memory, episodic memory retrieval and visual awareness are being undertaken (Naghavi and Nyberg, 2005). This is of particular interest because these processes are often affected in people with schizophrenia (Blasi et al., 2010; Ranganath et al., 2003). In addition, decreased levels of $\left[{ }^{3} \mathrm{H}\right]$ pirenzepine binding and CHRM1 mRNA in BA6 have been reported in people with schizophrenia (Dean et al., 2008; Mancama et al., 2003). Thus, in our current studies, we measured levels of $\left[{ }^{3} \mathrm{H}\right]$ pirenzepine binding in BA6 from people with schizophrenia who had low $\left(\right.$ SzLow $\left.\left[{ }^{3} \mathrm{H}\right] \mathrm{PZP}\right)$ and relatively unchanged (SzNormal[ $\left.{ }^{3} \mathrm{H}\right] \mathrm{PZP}$ ) levels of $\left[{ }^{3} \mathrm{H}\right]$ pirenzepine binding in BA9 and in age sex matched controls. In addition, we determined if changes in CHRM1 may be somewhat selective by measuring levels of $\mathrm{CHRM} 3$ using a modified radioligand binding technique (Jeon et al., 2013) and of mRNA for CHRM1, 3 and 4.

Notably, we have shown that there was no change in CHRM1 gene sequence associated with a change in levels of CHRM1 gene expression (Scarr et al., 2009), suggesting changes in levels of CHRM1 expression could be due to changes in transcriptional regulation. Importantly, assessing the putative promoter region of the human CHRM1 gene with Transcription Element Search System (TESS), which searches putative transcription binding sites in DNA sequence (http://www.cbil.upenn.edu/cgi-bin/tess/tess), identified a Sp1 binding site. Furthermore, this Sp1 site is reported to be capable of recruiting Sp1 in vitro (Wood et al., 1999) and, by interacting with Sp3, regulating levels of CHRM1 expression. One marker of a change in control of CHRM1 expression by this transcriptional regulation pathway would be changes in cellular localisation and ratio of Sp1 and Sp3 (Chuang et al., 2008; Li et al., 2004; Suske, 1999; Tan and Khachigian, 2009). Therefore, we measured the nuclear and cytosolic levels of Sp1 and Sp3 and their ratios as a surrogate measurement of whether changes in translocation of the transcription factors had occurred in SzLow $\left[{ }^{3} \mathrm{H}\right] \mathrm{PZP}$ group. 


\section{Materials and Methods}

\subsection{Human tissue collection, clinical follow up and diagnosis}

All human tissues were sourced though the Victorian Brain Bank Network, held at the Mental Health Research Institute. Approval for the study was obtained from both the Ethics Committee of the Victorian Institute of Forensic Medicine and the Mental Health Research and Ethics Committee of Melbourne Health. In order for the diagnosis of a psychiatric illness to be accepted, clinical case histories were used to reach a diagnostic consensus using the Diagnostic Instrument for Brain Studies (DIBS) (Hill et al., 1999), according to DSM-IV criteria (Roberts et al., 1998). Duration of illness (DOI), the final recorded antipsychotic drug dose (FRADD), lifetime exposure to antipsychotic drugs (LTEA), post-mortem interval (PMI) and CNS pH was recorded as described previously (Dean et al., 2008).

\subsection{Tissue preparation}

BA6, defined as the caudal portion of the superior frontal gyrus and the middle frontal gyrus extending from the cingulate sulcus on the medial surface to the lateral sulcus on the lateral surface, was collected from the left hemisphere of 58 subjects; 38 subjects with schizophrenia and 20 subjects with no history of psychiatric disorders. The 38 subjects with schizophrenia consisted of 18 subjects with SzNormal[ $\left[{ }^{3} \mathrm{H}\right] \mathrm{PZP}$ and 20 subjects with SzLow $\left[{ }^{3} \mathrm{H}\right] \mathrm{PZP}$, all matched as closely as possible for donor age, PMI, brain pH, sex, and DOI, death by suicide, FRADD, LTEA or prescription of anticholinergics and benzodiazepines in the schizophrenia groups (Table 1).

\subsection{In Situ radioligand binding with autoradiography}

Radioligand binding was performed using single-point saturation methods as described previously (Dean et al., 1996), which give a good approximation of the density of radioligand binding sites (Pavey et al., 2002) in tissue sections. The use of autoradiography provides information regarding the anatomical distribution of binding.

Tissue sections $(20 \mu \mathrm{m})$ were incubated with radioligand in the presence (non-specific binding (NSB): 2 sections) or absence (total binding (TB): 3 sections) of a competing displacing agent. $\left[{ }^{3} \mathrm{H}\right]$ pirenzepine binding was performed as described previously (Dean et al., 1996). For [ $\left.{ }^{3} \mathrm{H}\right] 4-\mathrm{DAMP}$ binding, the sections were pre-incubated in assay buffer $(50 \mathrm{mM}$ Tris- $\mathrm{HCl}(\mathrm{pH} 7.4))$ for $15 \mathrm{~min}$ at room temperature and then $\left[{ }^{3} \mathrm{H}\right] 4$-DAMP was incubated for $1 \mathrm{hr}$ in assay buffer containing the radioligand $(6$ $\mathrm{nM}$ ) (PerkinElmer, MA, USA) and $1 \mathrm{\mu M}$ pirenzepine (Sigma-Aldrich, MO,USA) in the presence (2 sections: NSB) or absence (3 sections: TB) of $10 \mu \mathrm{M}$ 4-DAMP mustard (Sigma-Aldrich, MO,USA) (Jeon et al., 2013). The sections were apposed to BAS-TR2025 phosphoimage plates (Fujifilm, Tokyo, Japan) with $\left[{ }^{3} \mathrm{H}\right]$ microscales $^{\mathrm{TM}}$ (G.E. Healthcare, UK) for 3 days. The plates were scanned in a 
BAS5000 high resolution phosphoimager (Fujifilm, Tokyo, Japan). The resulting images were analysed using analytical imaging station (AIS) imaging software (Imaging Research, St. Catharines, $\mathrm{ON}$, Canada), and the total minus non-specific binding (specific binding) was expressed as $\mathrm{fmol} / \mathrm{mg}$ estimated tissue equivalents (ETE) (Pavey et al., 2002).

\subsection{RNA purification and first strand cDNA synthesis}

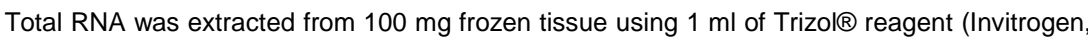
Carlsbad, CA) according to the manufacturer's instructions. RNA quantity and quality were determined by spectrophotometer readings and RNA integrity numbers (RINs). DNA contamination was checked by PCR using primers specific for genomic DNA. Total RNA was reverse transcribed into cDNA as previously described (Udawela et al., 2011).

\subsection{Real-time PCR assay}

Real-time PCR was performed using a Bio-Rad iQ5 real-time PCR detection system (Bio-Rad Laboratories, CA, USA) as previously described (Udawela et al., 2011). Oligonucleotides were designed using Beacon Designer 6.00 software (premier Biosoft, Palo Alto, CA, USA; see table 2). The identities of the amplicons were confirmed by sequencing. The cycling conditions for all genes in this study were $95^{\circ} \mathrm{C}$ for $3 \mathrm{~min}$ then 40 cycles of $95^{\circ} \mathrm{C}$ for $10 \mathrm{sec}, 57^{\circ} \mathrm{C}$ for $30 \mathrm{sec}$ and $72^{\circ} \mathrm{C}$ for $30 \mathrm{sec}$. The mRNA expression was determined using the Pfaffl method (Pfaffl, 2001), employing the standard curve efficiency. Expression was normalised against the geometric mean of three reference genes: Glyceraldehyde 3-phosphate dehydrogenase (GAPDH), Cyclophillin A (PPIA) and Alpha-synuclein (SNCA), selected as the most stable from 9 reference genes in post-mortem CNS tissue using geNorm software ( $M=1.398,1.386$ and 1.407, respectively) (Vandesompele, geNorm.).

\subsection{Tissue preparations for Western blots}

Whole tissue homogenates were prepared as previously described (Dean et al., 2008). To prepare subcellular fractions, tissue was homogenised in $1 \mathrm{ml}$ homogenisation buffer $\left(1 \mathrm{mM} \mathrm{CaCl}_{2}, 5\right.$

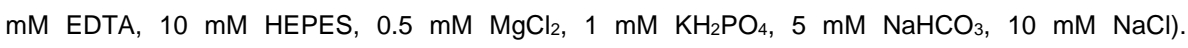
Subsequently, $150 \mu \mathrm{l}$ of $2.5 \mathrm{M}$ sucrose was added to each sample, which was then centrifuged at $6,300 \mathrm{~g}$ for $10 \mathrm{~min}$ at $4^{\circ} \mathrm{C}$. The supernatant was collected and stored as the membrane, organelle and cytoplasmic fraction. The pellet, containing the nuclei, was resuspended in $500 \mu \mathrm{l}$ of Tris-SucroseEDTA buffer (TSE buffer; $10 \mathrm{mM}$ Tris- $\mathrm{HCl}$ (pH 7.4), 1 mM EDTA, $300 \mathrm{mM}$ Sucrose, 0.1\% IGEPAL-CA 630), centrifuged at $4,000 \mathrm{~g}$ for $5 \mathrm{~min}$ at $4^{\circ} \mathrm{C}$ and the supernatant discarded. The pellet was then resuspended in $100 \mu$ l of whole tissue homogenisation buffer $(10 \mathrm{mM}$ Tris- $\mathrm{HCl}(\mathrm{pH} 7.4), 1 \%$ SDS, 1 $\mathrm{mM} \mathrm{Na}_{3} \mathrm{VO}_{4}$ ). The supernatant containing the membrane, organelle and cytoplasmic fractions was 
centrifuged at $107,000 \mathrm{~g}$ for $30 \mathrm{~min}$ at $4^{\circ} \mathrm{C}$. This final supernatant fraction was used for cytosolic protein.

\subsection{Western blots}

Western blot analyses of Sp1 and Sp3 were performed using optimised protocols. Protein was separated on a SDS-PAGE and then transferred onto nitrocellulose membranes. For Sp1, the process was as previously described (Dean et al., 2008). For Sp3, the membranes were blocked with $5 \%$ bovine serum albumin (BSA) in Tris buffered saline (TBS) with $0.1 \%$ Tween 20 (Sigma-Aldrich, MO, USA) (0.1\% TTBS) for $1 \mathrm{hr}$ at room temperature and incubated with a 1:1,000 dilution of rabbit anti-human Sp3 antibody (D-20) (Santa Cruz, CA, USA) in blocking buffer overnight at $4^{\circ} \mathrm{C}$. In order to show that the process produced clean fractions with no cross-over of the subcellular fraction, a Western blot was conducted on nuclear and cytosol fractions using the subcellular markers, histone deacetylase 1 (HDAC1; nuclear marker) and beta-actin (cytosol marker) in each fraction. The membranes were incubated with a 1:1,000 dilution of rabbit anti-human HDAC1 antibody (Upstate, MA, USA) in $0.1 \%$ TTBS overnight at $4^{\circ} \mathrm{C}$ or a $1: 100,000$ dilution of mouse anti-human beta-actin antibody (Chemicon, MA, USA) in $0.1 \%$ TTBS for $1 \mathrm{hr}$ at room temperature. Secondary antibodies (DAKO, Glostrup, Denmark) were incubated at a 1:2,000 dilution of the goat anti-rabbit antibody IgG conjugated to HRP for HDAC1, Sp1 and Sp3 or a 1:2,000 dilution of goat anti-mouse antibody for beta-actin for $1 \mathrm{hr}$ at room temperature.

Antigenic bands were visualized using SuperSignal West Pico Chemiluminescent Substrate (Thermo Scientific, MA, USA). To control for intra and inter-blot variation, an internal control (IC) was employed as described previously (Dean et al., 2007). The sum intensity of the desired band was then determined from the image for each subject in the cohort. The each nuclear and cytosolic level of Sp1 and Sp3 were calculated by dividing by the sum intensity of total cellular Sp1 and Sp3 on that blot to obtain a distribution ratio in the levels of nuclear and cytosol fractions.

\subsection{Statistics}

The first series of analyses initially involved comparing data from all subjects with schizophrenia to control subjects. Subsequently, the subjects with schizophrenia were divided according to level of $\left.{ }^{3} \mathrm{H}\right]$ pirenzepine binding and analysis was performed comparing SzNormal[ $\left.{ }^{3} \mathrm{H}\right] \mathrm{PZP}$, SzLow $\left[{ }^{3} \mathrm{H}\right] \mathrm{PZP}$ and control subjects. Numerical demographic and all experimental measurement data were assessed for differences using a Generalized Linear Model (GLM) and the source of any variation was determined using Bonferroni Simultaneous Tests. The non-numerical demographic variables were compared using a Fisher's exact test between subjects with schizophrenia and control subjects and a chi squared test in SzNormal[ $\left.{ }^{3} \mathrm{H}\right] \mathrm{PZP}$ and SzLow $\left[{ }^{3} \mathrm{H}\right] \mathrm{PZP}$ and control subjects. To assess whether a relationship existed between experimental measurements 
and numerical demographic factors or RNA integrity numbers (RINs) for mRNA, Pearson's product moment correlations assuming a straight line best fit were performed. Due to small cohort sizes only strong relationships $\left(r^{2}>0.49\right)$ (Cook and Weisberg, 2011) where the regression deviated significantly were considered as being of interest. Where necessary, the impact of non-numerical demographic variables were analysed using an analysis of co-variance (ANCOVA). Statistics were conducted using Prism 5.01 (Graphpad Software, CA, USA) and Minitab version 16.1 (Minitab Inc. PA, USA) software.

\section{Results}

\subsection{CNS collection, clinical and pharmacological data}

Due to our experimental design, there were no significant differences between subjects with schizophrenia and control subjects for age $(F=0.02$, d.f. $=1,56, p=0.88)$, brain $p H(F=2.83$, d.f.=1,56, $p=0.10)$, PMI $(F=0.45$, d.f. $=1,56, p=0.50)$ or gender $(P=1$, Fisher's exact test $)$. When subjects with schizophrenia were divided into groups according to their levels of $\left[{ }^{3} \mathrm{H}\right]$ pirenzepine binding, Age $(F=0.22$, d.f. $=2,55, p=0.98)$, $P M I(F=0.37$, d.f. $=2,55, p=0.69)$, brain $\mathrm{pH}(F=1.95$, d.f. $=2,55, p=0.15)$ and gender ratio (Chi square $=0.04$, d.f. $=2, p=0.98$ ) did not differ across three groups. There was no significant difference between the schizophrenia groups in $D O I(F=0.00$, d. $f=1,36, p=0.98)$, FRADD $(F=0.08$, d.f. $=1,32, p=0.76)$, LTEA $(F=0.11$, d.f. $=1,32, p=0.74)$, the frequency of administration of anticholinergics ( $p=0.755$, Fisher's exact test), benzodiazepines $(p=0.76$, Fisher's exact test) or death by suicide $(p=0.73$, Fisher's exact test).

\section{$3.2\left[{ }^{3} H\right]$ irenzepine binding}

$\left[{ }^{3} \mathrm{H}\right]$ pirenzepine binding showed differential distribution across the cortical layers (Figure $1 \mathrm{~A}$ ). A previous study from our laboratory, comparing $\left[{ }^{3} \mathrm{H}\right]$ pirenzepine binding to cresyl violet stained sections, has shown that the outer binding layer overlays cortical laminae I to III whilst the inner layer covers laminae IV to VI (Dean et al., 2008). However, as the densities of $\left[{ }^{3} \mathrm{H}\right]$ pirenzepine binding showed strong correlations between outer and inner layers in each group (Con: $r^{2}=0.60, p<0.0001 ; \mathrm{Sz}$ : $r^{2}=0.96, p<0.0001$; SzNormal[ $\left.{ }^{3} H\right] P Z P: r^{2}=0.79, p<0.0001$; SzLow $\left.\left[{ }^{3} H\right] P Z P: r^{2}=0.98, p<0.0001\right)$, the intensities were measured across the entire gray matter including outer and inner layers because the density within each layer was not an independent variable.

The GLM analysis revealed that $\left[{ }^{3} \mathrm{H}\right]$ pirenzepine binding showed significant variations with diagnosis $(F=34.80$, d.f. $=1,56, p<0.001$ (Figure $1 \mathrm{~B}$ ). Bonferroni Simultaneous Tests revealed that the variation with diagnosis was due to significant decreases in $\left[{ }^{3} \mathrm{H}\right]$ pirenzepine binding density in tissue from people with schizophrenia $(p<0.001)$ compared to that from controls.

When subjects with schizophrenia were divided into groups according to their levels of $\left[{ }^{3} \mathrm{H}\right]$ pirenzepine binding, the levels of $\left[{ }^{3} \mathrm{H}\right]$ pirenzepine binding varied significantly with groups $(\mathrm{F}=90.70$, 
d.f. $=2,55, p<0.001$; Figure $1 \mathrm{C}$ ). Bonferroni Simultaneous Tests revealed that the variance with groups was due to $\left[{ }^{3} \mathrm{H}\right]$ pirenzepine binding density being lower in both subjects with SzLow $\left[{ }^{3} \mathrm{H}\right] \mathrm{PZP}$ $(p<0.0001)$ and SzNormal $\left[{ }^{3} \mathrm{H}\right] \mathrm{PZP}(\mathrm{p}<0.01)$ compared to controls. $\left[{ }^{3} \mathrm{H}\right]$ pirenzepine binding density was also lower in subjects with SzLow $\left[{ }^{3} H\right] P Z P$ compared to SzNormal $\left[{ }^{3} H\right] P Z P(p<0.0001)$.

\subsubsection{Potential Biological Relationships}

As the levels of $\left[{ }^{3} \mathrm{H}\right]$ pirenzepine binding were decreased in subjects with SzLow $\left[{ }^{3} \mathrm{H}\right] \mathrm{PZP}$ levels of binding in BA6 were compared to that in BA9. There were strong correlations between binding in BA6 and BA9 in the group with SzLow $\left[{ }^{3} \mathrm{H}\right] \mathrm{PZP}\left(\mathrm{r}^{2}=0.80, \mathrm{p}<0.0001\right)$ that did not exist for SzNormal $\left[{ }^{3} \mathrm{H}\right] \mathrm{PZP}\left(\mathrm{r}^{2}=0.33, \mathrm{p}=0.01\right)$ or control subjects $\left(r^{2}<0.01, p=0.97\right)$.

\section{3 $\left[{ }^{3} H\right] 4-D A M P$ binding}

$\left[{ }^{3} \mathrm{H}\right]$ 4-DAMP binding was homogenous across all cortical layers in BA6 (Figure 2 A). Therefore, an integrated measure was taken across the gray matter. Densities of $\left[{ }^{3} \mathrm{H}\right] 4-\mathrm{DAMP}$ binding were not different between schizophrenia and control subjects ( $F=0.01$, d.f. $=1,56, p=0.94$, Figure $2 \mathrm{~B}$ ) or between SzNormal[ $\left.{ }^{3} \mathrm{H}\right] \mathrm{PZP}$, SzLow $\left[{ }^{3} \mathrm{H}\right] \mathrm{PZP}$ and control subjects $(\mathrm{F}=0.05, \mathrm{~d} . \mathrm{f}=2,55, p=0.95$, Figure 2 C).

\subsection{Real time-PCR}

In the RNA experiment, one of samples from a subject with schizophrenia (specifically, SzNormal[ $\left.{ }^{3} \mathrm{H}\right] \mathrm{PZP}$ ) was not given RIN value indicating degradation and low quality. Since it was not appropriate for gene expression analysis, this sample was excluded from the qPCR study.

There were no variations in levels of CHRM1, 3 and 4 mRNA in BA6 from subjects with schizophrenia compared to controls (CHRM1: $F=1.80$, d.f. $=1,55, p=0.19$; CHRM3: $F=0.98$, d.f. $=1,55$, $\mathrm{p}=0.33$; CHRM4: $\mathrm{F}=3.52$, d.f. $=1,51, \mathrm{p}=0.07$ ) (Figure $3 \mathrm{~A}$. C. and $\mathrm{E}$ ) or in low- and normal- $\left[{ }^{3} \mathrm{H}\right] \mathrm{PZP}$ binding groups compared to control (CHMR1: $F=1.19$, d.f. $=2,54, p=0.31$; CHRM3: $F=0.49$, d.f. $=2,54$, $p=0.62$; CHRM4: $F=1.73$, d.f. $=2,50, p=0.19$; Figure 3 B. D. and $F$ ). In 4 cases ( 1 sample for CON, 2 samples for SzNormal[ $\left[{ }^{3} \mathrm{H}\right] \mathrm{PZP}, 1$ sample for SzLow $\left[{ }^{3} \mathrm{H}\right] \mathrm{PZP}$ ), levels of mRNA for CHRM4 were below the sensitivity of the assay and these samples were excluded in the CHRM4 analysis.

\subsection{Western blots}

Importantly, we showed the subcellular protein markers, HDAC1 (nuclear) and beta-actin (cytosolic) were localised in the appropriate cellular fraction with negligible crossover (Figure 4 A) 
indicating a good separation of nuclei and cytosol. Although Sp1 and Sp3 have been reported to be distributed in nuclear and cytosol fractions (Van Wijnen et al., 1993), in human cortex we showed that Sp3 was mainly present in the nucleus whilst Sp1 was present in both fractions (Figure 4 B).

The levels of Sp1 (nuclear: $F=0.35$, d.f. $=1,56, p=0.55$; cytosolic: $F=0.01$, d.f. $=1,56, p=0.94$ ), Sp3 (nuclear: $F=0.00$, d.f. $=1,56, p=0.97$; cytosolic: $F=0.39$, d.f. $=1,56, p=0.54$ ) and the ratio of $S p 1 / S p 3$ (nuclear: $F=0.00$, d.f. $=1,56, p=0.98$; cytosolic: $F=0.80$, d.f. $=1,56, p=0.38$ ) did not vary between subjects with schizophrenia and controls (Figure $4 \mathrm{C}$. E). When schizophrenia was divided according to $\left[{ }^{3} \mathrm{H}\right]$ pirenzepine binding levels, the levels of $\mathrm{Sp} 1$ (nuclear: $\mathrm{F}=0.19$, d.f. $=2,55, p=0.83$; cytosolic: $F=0.07$, d.f. $=2,55, p=0.93$ ), $S p 3$ (nuclear: $F=0.33$, d.f. $=2,55, p=0.72$; cytosolic: $F=0.30$, d.f. $=2,55$, $p=0.74$ ) and the ratio of $\mathrm{Sp} 1 / \mathrm{Sp} 3$ (nuclear: $F=0.02$, d.f. $=2,55, p=0.98$; cytosolic: $F=0.43$, d.f. $=2,55$, $\mathrm{p}=0.65$ ) were not different in either nuclear or cytosolic fractions when compared between groups (Figure 4 D. F).

\subsection{Potential confounds}

There were no strong relationships with age, PMI, DOI, brain pH, FRADD or LTEA for any other of experimental data. In addition, an ANCOVA revealed that the levels of experimental measurements were not significantly affected by any categorical demographic data such as gender, death by suicide or prescription of benzodiazepines or anti-cholinergic drugs (see Supplementary Tables 1 and 2).

\section{Discussion}

This study shows that the density of $\left[{ }^{3} \mathrm{H}\right]$ pirenzepine binding is decreased in subjects with schizophrenia compared to control subjects and that the loss of radioligand binding that defined SzLow $\left[{ }^{3} \mathrm{H}\right] \mathrm{PZP}$ in BA9 is present in BA6. Although the group with schizophrenia that have normal levels of CHRM1 in BA9 also showed a decrease in CHRM1 in BA6, the magnitude of the decrease was much smaller. In additionlmportantly, there was no relationship strong association-between experimental data and any potential confounding factor examined in this study. However, there are factors that could not be fully addressed using the data we have available following our postmortem review, such as the full impact of while the data showed that potential confounding factors, like diagnosis, final doses and lifetime exposure equivalents to antipsychotic drugs, did not different in SzLOW ${ }^{3}$ HIPZP, we could not address etiopathobiology and other possible illness confounds, such as types of medications and their combinations, other non-pharmacological treatments, substance abuse, illness effects including decreased stimulation and institutionalization, medical comorbidity, and other comorbid psychiatric conditions. However, these are limitations associated with most, if not all, studies using postmortem CNS tissue in psychiatry-as there was no reliable information about

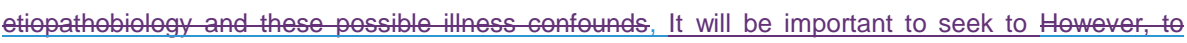


more-clarify any such relationships in the finding of a sub-groups of people with in SzLow[3H]PZP but this will likely need to be done in living individuals identified using neuroimaging, a future study could include assessing the etiopathobiology and other possible illness confounds. This finding will clarify the relationship whether levels of $\mathrm{I}^{3} \mathrm{H}$ lpirenzepine binding expression are likely to be mediating an effect on potential confounding factors. Furthermore, levels of $\left[{ }^{3} \mathrm{H}\right]$ pirenzepine binding in BA6 and BA9 were strongly correlated in the SzLow $\left[{ }^{3} \mathrm{H}\right] \mathrm{PZP}$, but not SzNormal[ $\left[{ }^{3} \mathrm{H}\right] \mathrm{PZP}$ or control groups. This strong relationship between levels of $\left[{ }^{3} \mathrm{H}\right]$ pirenzepine binding in the different brain regions from subjects with SzLow $\left[{ }^{3} \mathrm{H}\right] \mathrm{PZP}$ is possibly the result of altered regulation of CHRM1 expression in the brain and is consistent with our findings in other cortical regions (Gibbons et al., 2013) and in some individuals in a neuroimaging study of muscarinic receptor levels in people with schizophrenia (add Raedler reference here).

Levels of radioligand binding to CHRM3 and levels of CHRM 1, 3 and 4 mRNA were not changed in schizophrenia or in SzLow $\left[{ }^{3} \mathrm{H}\right] \mathrm{PZP}$ or SzNormal $\left[{ }^{3} \mathrm{H}\right] \mathrm{PZP}$. Notably, studies of radioligand binding to the five human CHRMs (M1-5) showed that anticholinergic drugs, such as benztropine, bound with high affinity to all CHRMs subtypes (Larson et al., 1991). Thus, our finding that there is not decrease in binding of cortical $\left[{ }^{3} \mathrm{H}\right] 4-\mathrm{DAMP}$ despite reductions in $\left[{ }^{3} \mathrm{H}\right]$ pirenzepine argue that residual anticholinergic drugs are not present in the tissue used in this study. Interestingly, this study showed that the level of CHRM1 mRNA was not changed in either group with schizophrenia. This result is contrary to the previous report of reduced expression of CHRM1 mRNA in BA6 from subjects with schizophrenia (Mancama et al., 2003). It is possible that the discrepancy between the studies arises because in this study we used 3 reference genes (GAPDH, PPIA, SCNA) compared to one reference gene (beta-actin) in the earlier study. This could be a significant difference given data suggesting that at least two or three reference genes should be used for normalization purposes to ensure variation in tissue processing are negated (Vandesompele et al., 2002).

We show that the levels and localisation of $\mathrm{Sp} 1$ and $\mathrm{Sp} 3$, or the ratio of these two proteins, are not different between subjects with schizophrenia and controls or schizophrenia divided according to $\left[{ }^{3} \mathrm{H}\right]$ pirenzepine status. These findings are consistent with an earlier study in BA6 which reported that levels of total $\mathrm{Sp} 1$ in crude homogenates were not changed in subjects with schizophrenia compared to controls (Dean et al., 2008) and suggest that the decrease in CHRM1 in schizophrenia cannot be simply related to changes in levels or localisation of Sp1 or Sp3. However, there are multiple layers of gene regulation including cell signaling, protein localization, modification and degradation, alterations in which could be responsible for the reduced CHRM1 expression seen in schizophrenia. More recently, a post-mortem study reported a significant upregulation of miR-107, which is predicted to target CHRM1, in BA9 samples from people with schizophrenia (Beveridge et al., 2010), and a study from our laboratory validated that miR-107 expression was increased in a subgroup of people with schizophrenia who have decreased CHRM1 expression in BA9 (Scarr et al., 2013). These data suggest that important factors, other than SP1 and SP3, may be driving the changes in levels of $\left[{ }^{3} \mathrm{H}\right]$ pirenzepine in BA6 from people with schizophrenia. 


\section{References}

Anagnostaras, S.G., Murphy, G.G., Hamilton, S.E., Mitchell, S.L., Rahnama, N.P., Nathanson, N.M., Silva, A.J., 2003. Selective cognitive dysfunction in acetylcholine M1 muscarinic receptor mutant mice. Nature neuroscience 6(1), 51-58.

Beveridge, N.J., Gardiner, E., Carroll, A.P., Tooney, P.A., Cairns, M.J., 2010. Schizophrenia is associated with an increase in cortical microRNA biogenesis. Molecular psychiatry 15(12), 1176-1189.

Blasi, G., Taurisano, P., Papazacharias, A., Caforio, G., Romano, R., Lobianco, L., Fazio, L., Di Giorgio, A., Latorre, V., Sambataro, F., Popolizio, T., Nardini, M., Mattay, V.S., Weinberger, D.R., Bertolino, A., 2010. Nonlinear response of the anterior cingulate and prefrontal cortex in schizophrenia as a function of variable attentional control. Cereb Cortex 20(4), 837-845.

Chuang, J.Y., Wang, Y.T., Yeh, S.H., Liu, Y.W., Chang, W.C., Hung, J.J., 2008. Phosphorylation by cJun $\mathrm{NH} 2$-terminal kinase 1 regulates the stability of transcription factor Sp1 during mitosis. Molecular biology of the cell 19(3), 1139-1151.

Cook, R., Weisberg, S., 2011. Applied Regression Including Computing and Graphics. Wiley: Hoboken.

Dean, B., Boer, S.A., Mackinnon, A., Berk, M., 2007. CNS 14-3-3zeta: changes with sex but not psychiatric diagnoses or psychotropic drug treatment. Schizophrenia research 93(1-3), 51-57.

Dean, B., Crook, J.M., Opeskin, K., Hill, C., Keks, N., Copolov, D.L., 1996. The density of muscarinic M1 receptors is decreased in the caudate-putamen of subjects with schizophrenia. Molecular psychiatry 1(1), 54-58.

Dean, B., Soulby, A., Evin, G.M., Scarr, E., 2008. Levels of [(3)H]pirenzepine binding in Brodmann's area 6 from subjects with schizophrenia is not associated with changes in the transcription factor SP1 or BACE1. Schizophrenia research 106(2-3), 229-236.

Gibbons, A.S., Scarr, E., Boer, S., Money, T., Jeon, W.J., Felder, C., Dean, B., 2013. Widespread decreases in cortical muscarinic receptors in a subset of people with schizophrenia. Int $\mathrm{J}$ Neuropsychopharmacol 16(1), 37-46.

Hill, C., Keks, N., Roberts, S., Opeskin, K., Dean, B., Copolov, D., 1999. Diagnostic Instrument for Brain Studies.

Jablensky, A., 2006. Subtyping schizophrenia: implications for genetic research. Molecular psychiatry 11(9), 815-836.

Jeon, W.J., Gibbons, A.S., Dean, B., 2013. The use of a modified [3H]4-DAMP radioligand binding assay with increased selectivity for muscarinic $M 3$ receptor shows that cortical CHRM3 levels are not altered in mood disorders. Prog Neuropsychopharmacol Biol Psychiatry.

Larson, E.W., Pfenning, M.A., Richelson, E., 1991. Selectivity of antimuscarinic compounds for muscarinic receptors of human brain and heart. Psychopharmacology 103(2), 162-165.

Li, L., He, S., Sun, J.M., Davie, J.R., 2004. Gene regulation by Sp1 and Sp3. Biochemistry and cell biology = Biochimie et biologie cellulaire 82(4), 460-471.

Mancama, D., Arranz, M.J., Landau, S., Kerwin, R., 2003. Reduced expression of the muscarinic 1 receptor cortical subtype in schizophrenia. American journal of medical genetics. Part B, Neuropsychiatric genetics : the official publication of the International Society of Psychiatric Genetics 119B(1), 2-6. 
Naghavi, H.R., Nyberg, L., 2005. Common fronto-parietal activity in attention, memory, and consciousness: shared demands on integration? Consciousness and cognition 14(2), 390-425.

Nathan, P.J., Watson, J., Lund, J., Davies, C.H., Peters, G., Dodds, C.M., Swirski, B., Lawrence, P., Bentley, G.D., O'Neill, B.V., Robertson, J., Watson, S., Jones, G.A., Maruff, P., Croft, R.J., Laruelle, M., Bullmore, E.T., 2012. The potent M1 receptor allosteric agonist GSK1034702 improves episodic memory in humans in the nicotine abstinence model of cognitive dysfunction. Int $J$ Neuropsychopharmacol, 1-11.

Pavey, G.M., Copolov, D.L., Dean, B., 2002. High-resolution phosphor imaging: validation for use with human brain tissue sections to determine the affinity and density of radioligand binding. Journal of neuroscience methods 116(2), 157-163.

Pfaffl, M.W., 2001. A new mathematical model for relative quantification in real-time RT-PCR. Nucleic acids research $29(9)$, e45.

Raedler, T.J., Bymaster, F.P., Tandon, R., Copolov, D., Dean, B., 2007. Towards a muscarinic hypothesis of schizophrenia. Molecular psychiatry 12(3), 232-246.

Ranganath, C., Johnson, M.K., D'Esposito, M., 2003. Prefrontal activity associated with working memory and episodic long-term memory. Neuropsychologia 41(3), 378-389.

Roberts, S.B., Hill, C.A., Dean, B., Keks, N.A., Opeskin, K., Copolov, D.L., 1998. Confirmation of the diagnosis of schizophrenia after death using DSM-IV: a Victorian experience. The Australian and New Zealand journal of psychiatry 32(1), 73-76.

Scarr, E., Cowie, T.F., Kanellakis, S., Sundram, S., Pantelis, C., Dean, B., 2009. Decreased cortical muscarinic receptors define a subgroup of subjects with schizophrenia. Molecular psychiatry 14(11), 1017-1023.

Scarr, E., Craig, J.M., Cairns, M.J., Seo, M.S., Galati, J.C., Beveridge, N.J., Gibbons, A., Juzva, S., Weinrich, B., Parkinson-Bates, M., Carroll, A.P., Saffery, R., Dean, B., 2013. Decreased cortical muscarinic $\mathrm{M} 1$ receptors in schizophrenia are associated with changes in gene promoter methylation, mRNA and gene targeting microRNA. Translational psychiatry 3, e230.

Scarr, E., Dean, B., 2008. Muscarinic receptors: do they have a role in the pathology and treatment of schizophrenia? Journal of neurochemistry 107(5), 1188-1195.

Suske, G., 1999. The Sp-family of transcription factors. Gene 238(2), 291-300.

Tan, N.Y., Khachigian, L.M., 2009. Sp1 phosphorylation and its regulation of gene transcription. Molecular and cellular biology 29(10), 2483-2488.

Udawela, M., Scarr, E., Hannan, A.J., Thomas, E.A., Dean, B., 2011. Phospholipase C beta 1 expression in the dorsolateral prefrontal cortex from patients with schizophrenia at different stages of illness. The Australian and New Zealand journal of psychiatry 45(2), 140-147.

Van Wijnen, A.J., Bidwell, J.P., Fey, E.G., Penman, S., Lian, J.B., Stein, J.L., Stein, G.S., 1993. Nuclear matrix association of multiple sequence-specific DNA binding activities related to SP-1, ATF, CCAAT, C/EBP, OCT-1, and AP-1. Biochemistry 32(33), 8397-8402.

Vandesompele, J., geNorm. http://medgen.ugent.be/ jivdesomp/genorm/.

Vandesompele, J., De Preter, K., Pattyn, F., Poppe, B., Van Roy, N., De Paepe, A., Speleman, F., 2002. Accurate normalization of real-time quantitative RT-PCR data by geometric averaging of multiple internal control genes. Genome biology 3(7), RESEARCH0034. 
Wood, I.C., Garriga, M., Palmer, C.L., Pepitoni, S., Buckley, N.J., 1999. Neuronal expression of the rat M1 muscarinic acetylcholine receptor gene is regulated by elements in the first exon. The Biochemical journal 340 ( Pt 2), 475-483.

Figure legends.

Figure 1. A: A representative autoradiograph of $\left[{ }^{3} \mathrm{H}\right]$ pirenzepine binding to human $B A 6$ with nonspecific binding shown as an inset. The image shows two layers of radioligand binding (layer 1 and layer 2) and white matter. B: Graphical depiction (Mean \pm s.e.m.) of $\left[{ }^{3} \mathrm{H}\right]$ pirenzepine binding BA6 from subjects with schizophrenia and control subjects. C: $\left[{ }^{3} \mathrm{H}\right]$ pirenzepine binding in control, SzNormal[ $\left.{ }^{3} \mathrm{H}\right] \mathrm{PZP}$ group and SzLow $\left[{ }^{3} \mathrm{H}\right] \mathrm{PZP}$ group. ${ }^{* *} p<0.01$, and ${ }^{* * *} p<0.001$.

Figure 2. A: Representative autoradiographs of otal and non-specific (insert) binding of $\left[{ }^{3} \mathrm{H}\right] 4-\mathrm{DAMP}$ in BA6. B: Graphical representation (Mean \pm s.e.m) of $\left[{ }^{3} \mathrm{H}\right] 4-\mathrm{DAMP}$ binding in subjects with schizophrenia and control subjects. C: $\left[{ }^{3} \mathrm{H}\right] 4-\mathrm{DAMP}$ binding in control, SzNormal[ $\left.{ }^{3} \mathrm{H}\right] \mathrm{PZP}$ group and SzLow $\left[{ }^{3} \mathrm{H}\right] \mathrm{PZP}$ group.

Figure 3. Relative mRNA expression of CHRM1 (Mean \pm s.e.m. ratio of 3 reference genes: A: tissue from control subjects and subjects with schizophrenia and B: control, SzNormal[ $\left.{ }^{3} \mathrm{H}\right] \mathrm{PZP}$ group and SzLow $\left[{ }^{3} \mathrm{H}\right] \mathrm{PZP}$ group). Relative mRNA expression of CHRM3 (Mean \pm s.e.m. ratio of 3 reference genes: $\mathbf{C}$ : control subjects and subjects with schizophrenia and $\mathbf{D}$ : 
control, SzNormal[ $\left.{ }^{3} \mathrm{H}\right] \mathrm{PZP}$ group and SzLow $\left[{ }^{3} \mathrm{H}\right] \mathrm{PZP}$ group). Relative mRNA expression of CHRM4 (Mean \pm s.e.m. ratio of 3 reference genes: $E$ : control subjects and subject with schizophrenia and F: control, SzNormal[ $\left.{ }^{3} \mathrm{H}\right] \mathrm{PZP}$ group and SzLow $\left[{ }^{3} \mathrm{H}\right] \mathrm{PZP}$ group).

Figure 4. A: Representative images of HDAC1 (N: nuclear protein), beta-actin (C: cytosol protein) and B: Sp1 and Sp3 in subcellular fractions using Western blotting. Sp1 and Sp3 in nuclear and cytosol protein (Mean \pm s.e.m. ratio of whole protein: C: control subjects and subjects with schizophrenia and D: control, SzNormal[ $\left.{ }^{3} \mathrm{H}\right] \mathrm{PZP}$ group and SzLow $\left[{ }^{3} \mathrm{H}\right] \mathrm{PZP}$ group. Ratio of Sp1 to Sp3 in nuclear protein (Mean \pm s.e.m. ratio of Sp1 to Sp3: $\mathbf{E}$ : control subjects and subjects with schizophrenia and F: control, SzNormal[ $\left.{ }^{3} \mathrm{H}\right] \mathrm{PZP}$ group and SzLow $\left[{ }^{3} \mathrm{H}\right] \mathrm{PZP}$ group.

Figure 1. $\left[{ }^{3} \mathrm{H}\right]$ pirenzepine binding assay 
Fig. 1

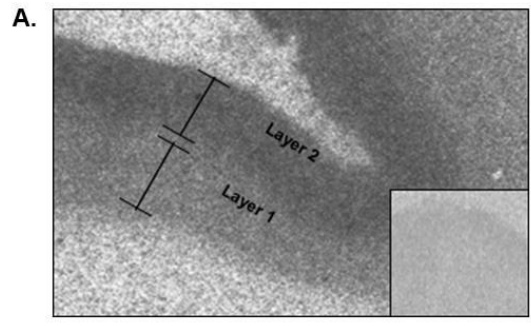

B.

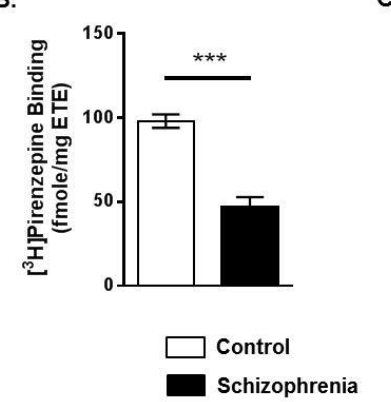

c.

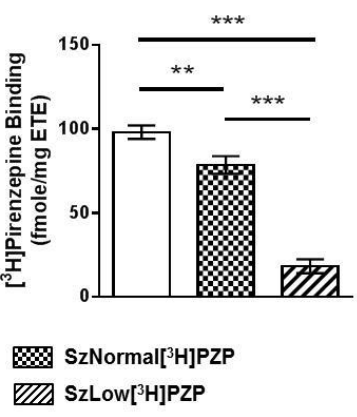

Figure 2. $\left[{ }^{3} \mathrm{H}\right] 4-\mathrm{DAMP}$ binding assay 
Fig. 2

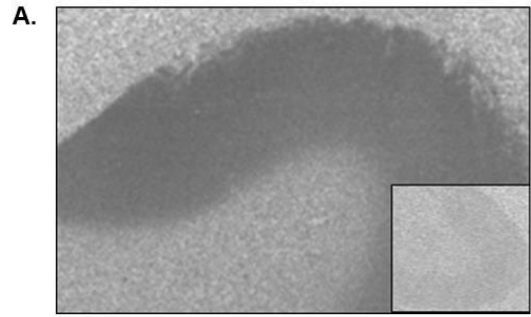

B.

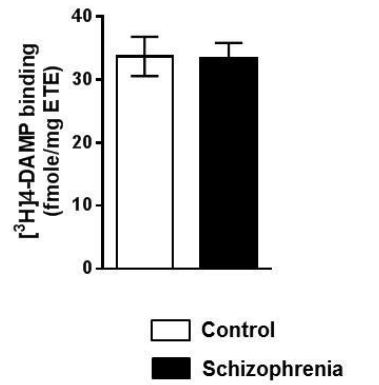

c.

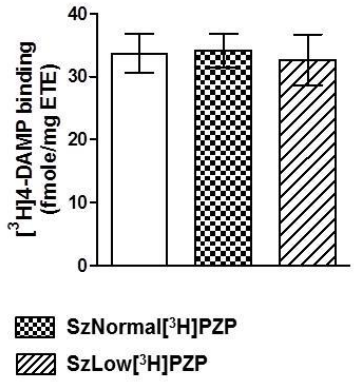

Figure 3. The levels of CHRMs mRNA 
Fig. 3
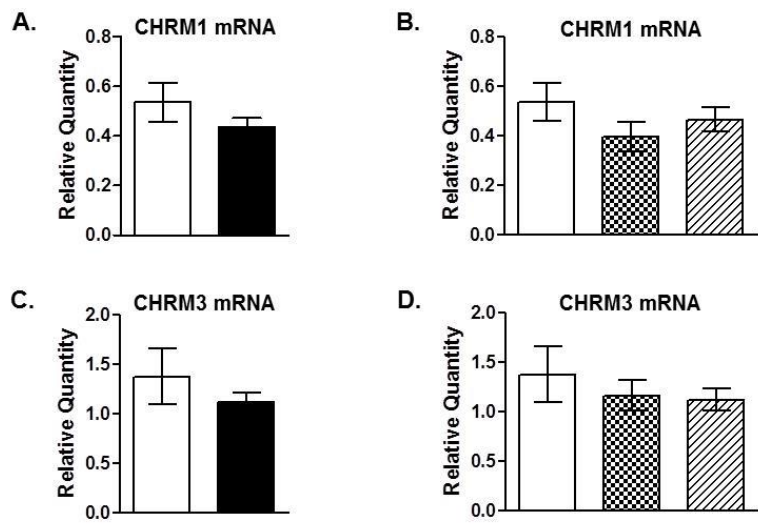

E.

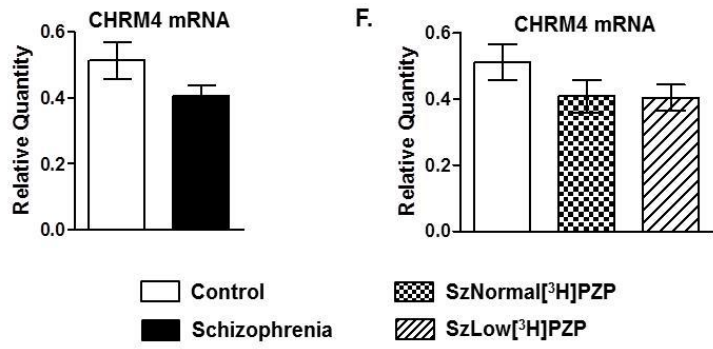

Figure 4. The levels of Sp1 and Sp3 in subcellular fractions 
A

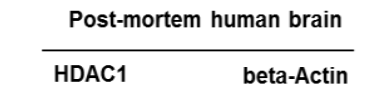

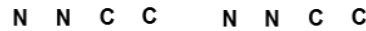

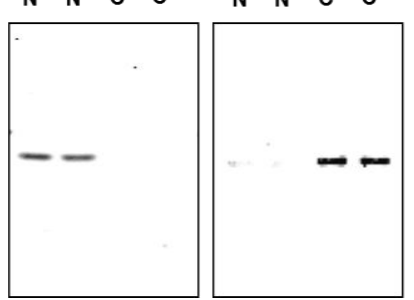

C.
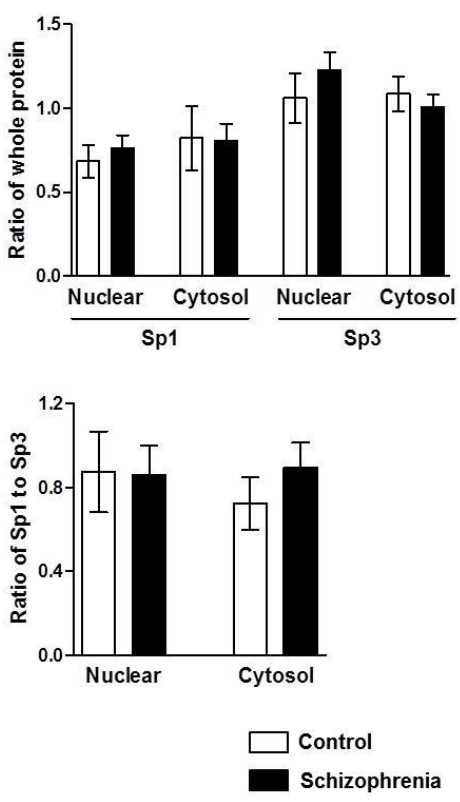

B
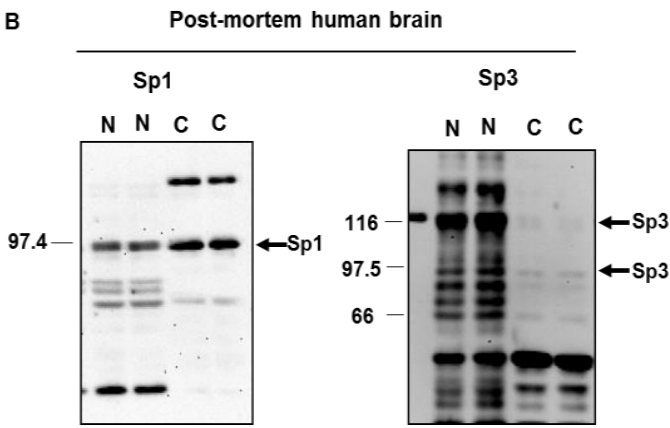

D.

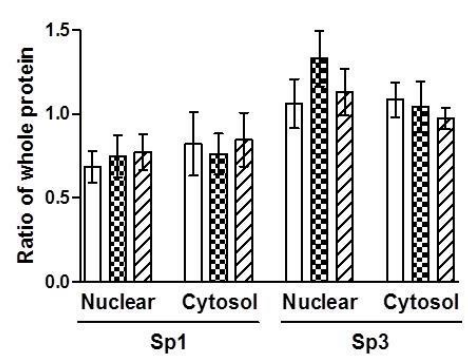

F.

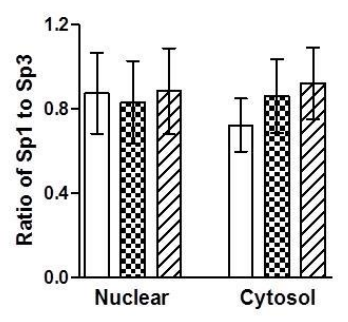

Q8 SzNormal[ $\left.{ }^{3} \mathrm{H}\right] \mathrm{PZP}$

WII SzLow[ $\left.{ }^{3} \mathrm{H}\right] \mathrm{PZP}$

Table 1: A summary of the demographic and collection data (Mean \pm s.e.m) for the cohort used in this study in post-mortem brain tissue from BA6. 


\begin{tabular}{|c|c|c|c|c|}
\hline Diagnosis & Control & Sz & SzNormal[ $\left.{ }^{3} \mathrm{H}\right] \mathrm{PZP}$ & SzLow $\left[{ }^{3} \mathrm{H}\right] \mathrm{PZP}$ \\
\hline Age (yr) & $46 \pm 4$ & $46 \pm 3$ & $47 \pm 4$ & $46 \pm 4$ \\
\hline PMI (h) & $43 \pm 3.4$ & $40 \pm 2.1$ & $42 \pm 3.0$ & $39 \pm 2.7$ \\
\hline Brain pH & $6.32 \pm 0.05$ & $6.21 \pm 0.04$ & $6.18 \pm 0.06$ & $6.25 \pm 0.04$ \\
\hline $\operatorname{Sex}(M / F)$ & $16 \mathrm{M} / 4 \mathrm{~F}$ & $30 \mathrm{M} / 8 \mathrm{~F}$ & $14 \mathrm{M} / 4 \mathrm{~F}$ & $16 \mathrm{M} / 4 \mathrm{~F}$ \\
\hline DOI (yr) & NA & $20 \pm 2$ & $20 \pm 4$ & $20 \pm 4$ \\
\hline Suicide & NA & $26 \mathrm{~N} / 12 \mathrm{Y}$ & $13 N / 5 Y$ & $13 N / 7 Y$ \\
\hline FRADD & NA & $634 \pm 98$ & $670 \pm 163$ & $593 \pm 124$ \\
\hline LTEA & NA & $12.3 \pm 2.8$ & $11 \pm 4.0$ & $13.2 \pm 4.1$ \\
\hline Anti-cholinergics & NA & $19 N / 19 Y$ & $10 \mathrm{~N} / 8 \mathrm{Y}$ & $9 \mathrm{~N} / 11 \mathrm{Y}$ \\
\hline Benzodiazepines & NA & $14 N / 17 Y$ & $13 N / 8 Y$ & $11 \mathrm{~N} / 9 \mathrm{Y}$ \\
\hline $\begin{array}{l}\text { PMs: PMI: } \\
\text { antipsy } \\
\text { applica }\end{array}$ & otic drug & al, DOI & $\mathrm{n}$ of III & $\begin{array}{l}\text { DD: Final recorded } \\
\text { otic drugs, NA: Not }\end{array}$ \\
\hline
\end{tabular}

Table 2: A summary of the oligonucleotide primers used for an analysis of CHRMs expression.

\begin{tabular}{cl}
\hline Gene & \multicolumn{1}{c}{ Oligonucleotide sequence } \\
\hline \multirow{2}{*}{ CHRM1 } & F 5'-GCTCTACTGGCGCATCTACC-3' \\
& R 5'-GCCTTCGTCCTCTTCCTCTT-3' \\
\hline \multirow{2}{*}{ CHRM3 } & F 5'-AGCAGCAGTGACAGTTGG-3' \\
& R 5'-GAGCACGATGGAGTAGATGG-3' \\
\hline \multirow{2}{*}{ CHRM4 } & F 5'-GTCCTGGTGAACACCTTCTG-3' \\
& R 5'-TCTTTTTAAAGGTGGCGTTG-3' \\
\hline \multirow{2}{*}{ GAPDH } & F 5'-TGCACCACCAACTGCTTAGC-3' \\
& R 5'-GGCATGGACTGTGGTCATGAG-3' \\
\hline \multirow{2}{*}{ PPIA } & F 5'-ATGGTCAACCCCACCGTGTTCTTCG-3' \\
& R 5'-CGTGTGAAGTCACCACCCTGACACA-3' \\
\hline \multirow{2}{*}{ SNCA } & F 5'-CTGCTGCTGAGAAACCAAA-3' \\
& R 5'-CTGCTCCCTCCACTGTCTT-3'
\end{tabular}

